\title{
What does decolonising the curriculum mean for STEM subjects?
}

\author{
Dr Monica Fernandes \\ Brunel University London, UK
}

\begin{abstract}
The concept of decolonising the curriculum is currently under widespread discussion in higher education. While it is clearer how this can be done in disciplines within Humanities and Social Sciences, it is less obvious how it may be achieved in the STEM subjects, which are based more on technical knowledge and problem-solving.
\end{abstract}

Keywords: decolonising the curriculum; inclusive teaching; STEM

\section{Introduction}

With the move towards decolonising the curriculum in institutions, how do the Science, Technology, Engineering and Mathematics (STEM) subjects diversify their curricula when they tend to be based on sums, formulas and problem-solving? This question will be explored through considering what 'decolonising the curriculum' means as a concept and considering how this can take place in practice in STEM subjects.

\section{What does 'decolonising the curriculum' mean?}

The background of decolonising the curriculum can be traced to 2015, with the 'Rhodes Must Fall' protests at the University of Cape Town in South Africa. The South African context, with the backdrop of apartheid in its history, challenged the wider education system and advocated decolonising education in a bid to diversify narratives and perspectives. While at first glance this can be interpreted as a political notion, on closer inspection from a wider viewpoint on the education system, it also calls on educators to consider inclusive pedagogy, where inclusive curriculum design is at the forefront and students have a say in what they are taught and how (Florian and Black-Hawkins, 2011). From this perspective, decolonising the curriculum may be seen as a twofold process, allowing academics to consider 1) what is taught and 2) the way in which it is taught. As educators, we need to review what we teach. Decolonising the curriculum means going beyond Western models or theories and including various perspectives and voices, often without race and gender constraints. Rethinking what we teach allows students to be exposed to various contexts, views and opinions, so contributing to their development as independent learners and critical thinkers.

We also need to consider how we teach. This an opportunity to redesign curricula so that they are based on such inclusive approaches as diversifying assessments, using inclusive language, reviewing the skills that we want students to develop in our modules and considering various teaching platforms to ensure that all students have 
equal access to module materials. Students can be consulted to get a sense both of what they want the module content to be and how they would like it to be taught.

On an institutional and sector level, there is additional pressure to address decolonising education. The black, Asian and minority ethnic (BAME) student awarding-gap data illustrates that black students are the most disadvantaged. In $2018 / 19$, there was a $22.1 \%$ difference between the numbers of black students and white students who obtained either a first or upper second class of degree (OFS, 2020). To address this discrepancy, the Office for Students (OFS) highlighted nine 'key features', one of which was for institutions to 'review curriculum, teaching and learning practices' (OFS, 2020).

\section{How can STEM subjects be decolonised?}

What does decolonising the curriculum look like for STEM subjects - disciplines which are more technical or problem-solving? One way could be to include the history, philosophy and evolution of science subjects (Raju, 2012) and perhaps include more diverse individuals or voices, by whom and by which racism and misogyny may be challenged (Akinbosede, 2020). There may also be scope to explore and include alternative methods to problem-solving that may be less familiar, but are practised in other countries and cultures (for example, teaching the Japanese model of multiplication or exploring how the comma is used in decimals in maths in other countries). Teaching alternative problem-solving techniques have two significant benefits: students learn that there are several ways to solve a problem, with consequent appeal to their different learning styles; they see that STEM subjects are not Eurocentric but have a diverse background (Nhemachena, Hlabangane and Matowanyika, 2020). Such innovative approaches will undoubtedly challenge the nature of STEM subjects and could possibly bridge the gap that currently divides STEM from Social Sciences/Humanities.

The challenge of decolonising the curriculum in STEM subjects is the belief that science is objective and neutral (Bhambra, Gebrial and Nisancłolu, 2018). To overcome the challenge of neutrality, we academics need to reassess how we think of STEM subjects. Some have suggested re-orientating science in the wider body of knowledge to make it more inclusive (Bhambra, Gebrial and Nisancłolu, 2018) and thereby more truly objective, as it's taking into account multiple and diverse perspectives (Future Learn: n.d). While STEM subjects might be presented as neutral disciplines, the context in which these subjects emerged was not. How and why were theories developed and by whom? Part of inclusivity is to recognise where knowledge has come from and which individuals contributed to these disciplines. To do this means that those contributory voices, so far eliminated from the narrative, will now be heard - as they should be. For example, Chien-Shiung Wu, an AmericanChinese female physicist who specialised in beta decay, provided experimental evidence for theoretical physicists Chen Ning Yang and Tsung-Dao Lee, which led to their being awarded the Nobel Prize for Physics in 1957 (Johnston, 2020). Wu's contribution, like that of many others, hasn't been acknowledged, but decolonising the curricula may correct that, for it has created an opportunity to introduce new knowledge and inspire students who question the lack of representation of 
marginalised groups in their subjects, for they wish to see themselves represented in the subjects they are taught.

\section{Conclusion}

Decolonising the curriculum enables educators to rethink what is taught and how it is delivered. It allows for a more holistic, inclusive and creative approach to the designing of modules and curricula and also encourages a dialogue to take place between educators and students. STEM subjects are not exempt from having to review their curricula; if such measures are taken, there may well be more coherence between the sciences and humanities, where individuals and different perspectives on theories are included.

\section{Reference list}

Akinbosede, D. (2020) 'Science curricula must be decolonised too.' Times Higher Education, 5 June 2020. Available at:

https://www.timeshighereducation.com/blog/science-curricula-must-be-decolonisedtoo (Accessed: 11 February 2021).

Bhambra, G.K., Gebrial, D. and Nisancloglu, K. (2018) Decolonising the University. 1st edition. London, Pluto Press. ISBN: 9780745338200

Florian, L. and Black-Hawkins, K. (2011) 'Exploring inclusive pedagogy.' British Educational Research Journal, 37(5), 813-828. Available at: https://berajournals.onlinelibrary.wiley.com/doi/abs/10.1080/01411926.2010.501096 (Accessed: 8 February 2021).

Future Learn (n.d.) Interview with science journalist Angela Saini about decolonisation of STEM subjects. Available at:

https://www.futurelearn.com/info/courses/decolonising-education-from-theory-topractice/0/steps/189727 (Accessed: 20 April 2021).

Johnston, H. (2020) 'Overlooked for the Nobel: Chien- Shiung Wu.' Physics World. Available at: https://physicsworld.com/a/overlooked-for-the-nobel-chien-shiungwu/\#: :text=Overlooked\%3A\%20ChienShiung\%20Wu\%20in\%201963\%20at\%20Columbia\%20University.,led\%20to\%20imp ortant $\% 20$ discoveries $\% 20$ regarding $\% 20$ the $\% 20$ elementary\%20particles\%E2\%80\%9 D (Accessed: 8 February 2021).

Nhemachena, A., Hlabangane, N. and Matowanyika, J.Z.Z (2020) Decolonising science, technology, engineering and mathematics (STEM) in an age of technocolonialism: recentring African indigenous knowledge and belief systems. Mankon, Bamenda: Langaa Research \& Publishing CIG. ISBN: 9789956551866 
Office for Students (OFS) (2020) Degree Attainment: Black, Asian and minority ethnic students. Available at: https://www.officeforstudents.org.uk/advice-andguidance/promoting-equal-opportunities/effective-practice/black-asian-and-minorityethnic-students/ (Accessed: 26 February 2021).

Raju, C.K. (2012) 'Decolonising Math and Science Education.' In: Alvares, C. and Faruqi, S.S. (eds.) Decolonising the University: The Emerging Quest for NonEurocentric Paradigms. Malaysia: Penerbit Universiti Sains Malaysia and Citizens International. ISBN: 9789838615419 